\title{
PROFESSOR WILLIAM HUNTER MCCREA, FRS OBITUARY
}

\author{
Petros S. Florides \& Patrick Dolan
}

Sir William Hunter McCrea, one of the most distinguished astrophysicists, relativists and cosmologists of this century, died in Sussex on April 25, 1999. He was born in Ranelagh, Dublin, on December 13, 1904, the eldest son of Robert Hunter McCrea, a schoolmaster.

When 'Bill', as he was affectionately known, was two years old the family moved first to Kent and then settled in Chesterfield where his father took up a teaching post at Staveley Grammar School. Bill was educated at Chesterfield Grammar School. He entered Cambridge in 1923, having won a scholarship to Trinity College, where he read mathematics. Upon graduation in 1926 he started his research in astrophysics leading to a Ph.D. in 1929.

He moved to Edinburgh in 1929 as a lecturer in the Mathematics Department- headed, in those days, by Sir Edmund Whittaker who had been Astronomer Royal for Ireland and Director of the Dunsink Observatory from 1906 to 1912. In 1932 he was appointed Reader in Mathematics at Imperial College, London. Subsequently, in 1936, he was appointed Professor of Mathematics at the Queen's University, Belfast. In 1944 he moved to Royal Holloway College, University of London, and in 1966 to the newly established Astronomy Centre at the University of Sussex as its first Director.

McCrea made seminal contributions to astrophysics, cosmology and relativity. In 1928 he took up Unsoeld's hypothesis on the predominance of hydrogen in the atmosphere of the Sun and showed that three quarters of the Sun is hydrogen, one quarter helium and less than one per cent made up of the other chemical 
elements. This was a startling conclusion for its time, since the main constituent of the Sun was thought to be iron from the time of the Greek philosopher Anaxagoras of the 5th century B.C. Subsequently it was shown that the main constituent of every star is hydrogen. This result was to have great influence on cosmology. McCrea also made important contributions to the theory of the formation of stars and galaxies and of the Solar System.

In cosmology and relativity, McCrea made three lasting contributions. Firstly the creation, with E. A. Milne, of Newtonian cosmology which gave easily understood analogues of all the relativistic Robertson-Walker models of the universe. Secondly the formulation of suitable observational criteria which could discriminate between the different relativistic model universes and thirdly the reformulation of the Steady State Theory of the universe within Einstein's theory of general relativity. This latter work is now basic in models of the early universe which undergo a short period of inflationary expansion. In relativity proper, he is best known for his long controversy, in the late 1950's, with Professor H. Dingle on the so-called 'Twin Paradox' of the special theory of relativity.

Over the course of a long career McCrea wrote over 280 scientific papers, six books and he contributed some 250 reviews in the Zentralblatt für Mathematik.

McCrea was a member of the Royal Astronomical Society for seventy years, from 1929 until his death in 1999. Over those years he held every office of the Society from President downwards and was awarded the Society's Gold Medal in 1985. He was elected to the Royal Society in 1952, knighted in 1985 and became a Freeman of the City of London in 1988.

McCrea's connection with Ireland is deeply rooted, long and intimate. As well as being Irish by birth, he made an immense contribution to science in all of Ireland. During his eight years in Belfast, Armagh Observatory had been in decline and Dunsink Observatory, then part of Trinity College, Dublin, was, to all intents and purposes, closed. The re-emergence of these observatories as two viable reputable research institutions owes a great deal to McCrea's vision, advice and encouragement. 
In the late 1930's Mr de Valera, then Taoiseach, who was a keen mathematician and astronomer in his own right, was laying the foundations for the Dublin Institute for Advanced Studies. At a time when relations between Northern and Southern Ireland were anything but amicable, de Valera had the wisdom and the courage to call upon Professor McCrea for his advice and help. This McCrea gave readily and wholeheartedly. The subsequent re-opening of the Dunsink Observatory as part of the Institute is mainly due to McCrea's advice. McCrea served on the first Governing Board of the School of Theoretical Physics of the Institute.

McCrea was the prime mover in holding the third "out-oftown" meeting of the Royal Astronomical Society in Dublin in 1950-the first such meeting to be held outside the UK. It was so successful that two further such meetings were subsequently held in Dublin in 1965 and 1992, and another one in Belfast in 1962. Again, thanks to McCrea's efforts, the General Assembly of the International Astronomical Union was held in Dublin in 1955, as well as the 1957 annual meeting of the British Association for the Advancement of Science.

Appreciative of the great contribution that Bill McCrea made to science in Ireland, all the three Universities in Ireland (NUI, TCD, QUB) awarded him Honorary Doctorates-a rare, if not unique, distinction. The Royal Irish Academy also honoured him by electing him Member of the Society.

Despite his eminence in the scientific world Bill McCrea was a modest and unassuming man. He will always be remembered for his unfailing courtesy, help and encouragement to his many research students and fellow scientists at large.

His wife, Lady Marian McCrea, died in 1995 and he is survived by his two daughters, Isabella and Sheila, his son, Roderick, and seven grandchildren.

Petros S. Florides

School of Mathematics

Trinity College

Dublin 2

Ireland
Patrick Dolan

Department of Mathematics

Imperial College

London SW7 2BZ 